of growth is very similar to that observed by Harrison in amphibia and by Burrows in the chick when the material was taken from the central nervous system and transplanted into lymph or plasma. Since such growth does take place in fluid media, it is evident that the fibrin network is not essential for the outgrowth of the nerve fiber, nor is it necessary for the growth of other cells or the formation of long slender processes of various kinds. The under side of the cover-glass often seems to act as a support for the outgrowing cells and fibers. This adhesion of the growths to the cover-slip makes it possible to study the cultures to better advantage than otherwise since most of the growth is often in one plane.

The material which gave the best results was from embryo chicks less than ten days old. The cultures were grown in hanging drops.

\section{THE EFFECT OF INJECTIONS OF INDOL AND TYROSIN IN EXPERIMENTAL ANIMALS}

\section{A PRELIMINARY REPORT *}

PaUl G. WOOLley, M.D. and L. H. NEWBURGH, M.D. CINCINNATI

During the past year we commenced a series of experiments on rabbits and white rats, the object of which was to discover what relation chronic intoxications with some of the lower derivatives of protein decomposition bore to changes in the adrenals and kidneys. We had a suspicion that indol might have, in the process of secretion, or in the process of transformation into indican, or both, an effect in producing changes in the organs which would indicate hyperactivity of certain organs (the liver, and perhaps the adrenals) or irritative changes in others (the kidneys). There seemed to be some basis for this suspicion in the fact that indicanuria, especially when it is of well-marked degree, is accompanied by albuminuria and cylindruria. It seemed useful to discover, therefore, whether injections of indol would produce any noticeable changes in the kidneys; and, since the liver has been supposed to be the site of transformation into indican, it seemed possible that some changes in that organ might be expected. The tyrosin series had a different basis. We were interested in the physiology of the adrenal glands and had been led to suspect that the pigmentation of Addison's disease might be a result of variation in either the content of the chromaffin tissues in tyrosinase, or in the overabundance of tyrosin or some related substance in the body. This was indicated by the suggestion of von Fuirth that melanin and related bodies are the result of the action of tyrosinase or related oxydases on the aromatic constituents of the protein molecule, a suggestion which, as Adami says, has been supported by Halle, who demonstrated that tyrosin is converted into epinephrin by a ferment in the adrenal. Adami suggests that pigmentation in Addison's disease is produced when this ferment is deficient-when, in other words, the tyrosin is not converted into epinephrin by the adrenal, but into melanin in the skin. All of which induced us to attempt to discover whether tyrosin would stimulate the adrenals to increased activity or whether large excesses of tyrosin would produce melanosis in experi-

* From the Laboratories of the Cincinnati Hospital. * Read before the.Cincinnati Society of Medical Research, April 6, 1911 . mental animals. If the former were the case, we might expect to find as a result of increased epinephrin production either arterial changes or renal changes or both.

Finally, because of the similarity in origin of indol and tyrosin, we ran parallel series, each with its control.

We have no definite knowledge of the manner of action or of the effects of tyrosin in the organism. We know but little more concerning indol. We are led to think that massive doses of the latter may be consumed with no, or but little, ill effects in normal man (Nesbitt). Such effects are headache, insomnia, confusion and irritability (Herter), and, with decreased activity of the cells in disposing of such substances, intoxications are possible (Richards and Howland). It is, however, possible that comparatively small doses given over long periods of time may, even without producing symptoms, cause changes in the organs which may lead to very serious results.

Our series of experiments deal with the possibilities of such results.

In performing these experiments we used rabbits and white rats. Originally we used intravenous injections. Later we resorted to intraperitoneal injections. We used saturated aqueous solutions of Kahbaum's indol and tyrosin.

For the sake of brevity we shall at this time merely summarize our results by saying that after these injections we have found the medullas of the adrenals hyperplastic and apparently hypertrophic, and that the evidences of chromaffin activity increased in proportion to the number of injections. The chrome reaction is similarly increased. We also found very slight interstitial changes in the kidneys.

We had, at the commencement of our experiments, a suspected relation between tyrosin and adrenal changes; a suspicion of a possible relation between indol and renal changes; and the possibility of a relation between adrenal and renal changes.

From our incomplete results, the small importance of which we realize, we are not justified in drawing any conclusion, but we might suggest for the sake of perspective that, provided it be true that a true hyperactivity of the chromaffin is produced by one or other, or both of the substances we have used, or by other substances of the same chemical order, that is to say, belonging to the aromatic series. it might be suspected that such an hyperactivity, extending over a considerable period of time, may be a cause, perhaps the cause, of the symptom-complex known as diabetes. This would result from a change in the chromaffin-pancreas equilibrium.

Eppinger, to whom the idea possibly was suggested by Boinet, has remarked that tuberculin may be a substance which of itself produced inactivity of the chromaffin tissues of the bodv, and that by means of tuberculin the pancreas-adrenal equilibrium can be upset on the adrenal side; that is to say, in the Addisonian direction. In other words, under the influence of tuberculin the glycolytic function of the organism is increased.

Our experiments in this direction have led us already to a temporary belief, at least, in Eppinger's conception. We have found that seven injections, each of $0.5 \mathrm{mg}$.; of tuberculin led to an increase of sugar consumption in rabbits. A normal rabbit after $50 \mathrm{gm}$. of glucose (by mouth) showed $0.43 \mathrm{gm}$. of glucose in the urine (1.7\% per cent.). The same rabbit after seven injections of tuberculin showed $0.0 \% \mathrm{gm}$. (0.35 per cent.). These results with tuberculin, especially in view of the fact that the medulla of the glands shows atrophy after tuberculin treatment, are interesting if considered with 
the fact that in the diagnosis of Addison's disease tuberculin should be used with the greatest circumspection. Our final suggestion is that it seems possible that tuberculin injection may be of value in the treatment of diabetes, because of its influence on the chromaffin, and, through that influence, because of its tendency to bring back-to correct-the adrenal-pancreas equilibrium. We are contimuing our work by carrying out a careful series of physiologic experiments.

\section{CONJUGAL TABES DORSALIS *}

\section{AUGUSTUS A. ESHNER, M.D.} PHII.ADELPHIA

Recent discoveries have thrown a strong light on certain hitherto suspected but mot definitively demonstrable relations of syphilis. The view that tabes dorsalis and paretic dementia are essentially of syphilitic origin has been finally established by the results of the serumcomplement reaction. For the purposes of this discussion tabes and paresis may be looked on as expressions of the same morbid process, in the one instance affecting especially the spinal cord, and in the other especially the brain. Not rarely the two affections are associated in the same patient. Of the large number of persons infected with syphilis, however, only a comparatively small proportion become tabetic or paretic. Negroes, although frequently syphilitic, rarely develop tabes or paresis. Perhaps they possess an inherent racial inmunity. An explanation for the disparity in the incidence of the two diseases must be sought in some special factor, whether on the part of the infected individual or on the part of the infecting virus. This may reside in a lowering of the resistance of the nervous system as a result of previous disease, or intoxication or traumatism, or other debilitating or exhausting influence; or in a particular and peculiar activity of the syphilitic infection. These forces may operate separately or jointly.

Occasionally tabes or paresis appears in several members of the same family, simultaneously or consecutively. Thus, husband and wife may be affected; sometimes in addition a second husband or wife, or one or more children. Under such circumstances syphilis is quite invariably the common etiologic factor. Each of those affected may present the same form of disease of the nervous system, or one may suffer from one and the other from another form. The association is not common, although probably more so than is apparent, as inquiry is not, as a rule, directed toward this point. Moreover, the disease of the nervous system does not usually appear sinultaneously in those affected, and the association may tor this reason be overlooked. That tabes and paresis are more prevalent among men than among women is most likely due to the fact that both affections are so often secondary to syphilis, and that this disease is usually acquired through illicit intercourse, an infected woman inoculating several men.

The occurrence of paretic dementia in husband and wife appears to have been recognized only since 1863 , when Kjellberg ${ }^{1}$ reported the first instances. Tabes dorsalis in husband and wife was first recorded bv Voigt ${ }^{2}$ in 1885 . Both patients presented evidences of syphilis, and.the venereal disease, as well as the disease

* Read before the Association of American Physicians, May 9 , 1911.

1. Cited by Idelson: St. Petersburg. med. Wchnschr., 1901,
xliii. 473 . 2. Centralbl. f. Nervenh., Psychiat. u. gericht. Psychopathol., of the nervous system, appeared the earlier in the man. Strümpell, ${ }^{3}$ in 1888 , reported a similar association and sequence. A comparatively small number of cases of like character have been reported since, largely from German sources. American literature contains a case recorded by $F$. Savary Pearce from the practice of $S$. Weir Mitchell, and refers to four other cases observed by Dr. Mitchell; a case recorded by A. P. Francine ${ }^{5}$ in a negro barber and his wife; and three cases of conjugal paretic dementia.recorded by Richard Dewev. ${ }^{6}$ Mendel. $^{7}$ in 1895, reported sixteen cases of conjugal tabes and paresis, and came to the conclusion that under such circumstances paresis occurs more commonly than tabes, and that the husband is almost invariably attacked first. Raecke, ${ }^{8}$ in 1899 , was able to tabulate sixty-nine cases of conjugal tabes and paresis, including seventeen of his own. In twenty-seven there was paresis in both; in twenty-two, tabes in both; in fourteen, paresis in husband and tabes in wife; in six, paresis in wife and tabes in husband. It thus appears that the husband is the more commonly paretic, the wife the more commonly tabetie. The former was generally attacked first.

Moenkemoeller, ${ }^{9}$ in 1900, reported eighteen additional cases and referred the usual occurrence of the disease in the husband first to the fact that he is generally syphilitic and infects his wife.

Idelson ${ }^{1}$ considers the incidence as more than accidental; else other disorders of the nervous system might be expected to occur in husband and wife with equal frequency. He reports the simultaneous appearance of paresis in husband and wife, both syphilitic at the same time. He was impressed by a certain uniformity in the course of the disease in the persons affected.

$\mathrm{Erb}^{10}$ concurs, from an abundant experience, in the view that the tabetic husband and wife are almost invariably syphilitic, the former generally infecting the latter, less commonly the wife the husband, and hoth becoming tabetic or paretic in succession.

Suntheim $^{11}$ has made a comprehensive study of conjugal tabes and paresis, reporting twenty-three previously unrecorded cases among 255 carefully studied patients seen in the course of six or seven years. Among 101 cases of tabes in men there were five in which the wife was similarly affected; among fifty-one cases in women there were nine in which the husband also was affected. In sixty-one cases of paresis in men there were five in which the wife also was affected, and among forty-two cases in women there were four in which the husband also was affected. Suntheim points out that while at the beginning the disease of the nervous system, as a rule, pursues the same course in husband and wife, there are differences in its subsequent evolution, the development being more rapid and the symptoms more pronounced in the second person attacked. Often the interval between the syphilitic infection and the appearance of the symptoms of the disease of the nervous system is the same in both. Suntheim found that the syphilitic infection was conveyed through the husband in ten instances as against one in which it was conveyed through the wife (and in this instance the disease was acquired by accident); symptoms of the nervous disorder appeared first in the husband in seven instances

\footnotetext{
3. Neurol, Centralbl., 1888, xvii, 122.

4. Jour. Nerv, and Ment. Dis., 1895. xx, 8.

5. Am. Jour. Med. Sc., 1900, cxix, 543.

6. Chicago Med. Recorder, October, 1893 , p. 233.

7. Neurol. Centralbl., 1895 , xiv, 335 .

8. Monatschr. f. Psychiat. u. Neurol., 1899, vi, 266.

9. Monatschr. f. Psychiat. u. Neurol., 1900, vii, 421.

9. Monatschr. f. Psychiat. u. Neurol.,
10. Berl. klin. Wchns chr., 1904, iii, 64.

11. Inaugural Dissertation, Leipsic, 1909.
} 